University for Business and Technology in Kosovo

UBT Knowledge Center

UBT International Conference

2017 UBT International Conference

Oct 28th, 9:00 AM - 10:30 AM

\title{
Research on system communication by using unified registry model \& elements
}

\author{
Kujtim Gashi \\ Agency for Information Society/Ministry of Public Administration, Pristina, Republic of Kosov, \\ kujtim.gashi@rks-gov.net \\ Atdhe Buja \\ University for Business and Technology, atdhe.buja@ubt-uni.net \\ Fatos Idrizi \\ Agency for Information Society/Ministry of Public Administration, Pristina, Republic of Kosov
}

Follow this and additional works at: https://knowledgecenter.ubt-uni.net/conference

Part of the Computer Engineering Commons, and the Computer Sciences Commons

\section{Recommended Citation}

Gashi, Kujtim; Buja, Atdhe; and Idrizi, Fatos, "Research on system communication by using unified registry model \& elements" (2017). UBT International Conference. 90.

https://knowledgecenter.ubt-uni.net/conference/2017/all-events/90

This Event is brought to you for free and open access by the Publication and Journals at UBT Knowledge Center. It has been accepted for inclusion in UBT International Conference by an authorized administrator of UBT Knowledge Center. For more information, please contact knowledge.center@ubt-uni.net. 


\title{
Research on system communication by using unified registry model \& elements
}

\author{
Kujtim Gashi ${ }^{1}$, Atdhe Buja ${ }^{1}$, Fatos Idrizi $^{1}$ \\ ${ }^{1}$ Agency for Information Society/Ministry of Public Administration, \\ Pristina, Republic of Kosovo \\ kujtim.gashi@rks-gov.net, atdhe.buja@ubt-uni.net, fatos.idrizi@rks-gov.net
}

\begin{abstract}
Trends of Development of Information Society in the Republic of Kosovo must fit the criteria and standards of the EU. The main objective of the paper is the identification of individual IT systems used by the Republic of Kosovo public institutions related to the trade and working out analysis and recommendations for optimizing their communication (interoperability), eventual unification in the hardware \& software level and increase the efficiency of the entire economic system information. The analytical analysis outlined these points, as it follows: current technologies used by public administration of the Republic of Kosovo, risk analysis, analysis of data structures and interfaces of Information Systems. For the synthetic analysis is outlined the points, as it follows: conceptual proposals technology integration.
\end{abstract}

Keywords: Information System, data model, electronic registry, communication

\section{Introduction}

The subject of this research was the communication between IT systems of state institutions in Kosovo, with particular emphasis on Trade and Industry systems. The reason for the realization of this research for country like Kosovo is facilitating its trade, building its trade capacities and activities, better integrating the country into the international trading system, helping the state administration to draft trading policies and frameworks, rules and strategies for removing administrative barriers, promoting the business climate and so on. The main objective of the paper is the identification of individual IT systems used by the Republic of Kosovo public institutions related to the trade and working out analysis and recommendations for optimizing their communication (interoperability), eventual unification in the hardware \& software level and increase the efficiency of the entire economic system information.

Further development of information systems should respect and help create the conditions for computerization of society, which is the process of the extended use of standardized equipment, software and tools, more precisely the systems to collect, process, transmission, dissemination and use of information. The process of computerization of public administration requires radically changing the basics, forms and methods of work and creating the conditions for the implementation of such instruments, which correspond to the needs of the emerging development of information society. From the experience of developed countries, it is clear that the process of unification of databases has lasted for years. Public administration and business are significantly decentralizing their powers to lower levels and leave them with a series of 
decisions, but carry out full control over the fulfillment of the objectives. An example is the development and access to the elaborated system under the United Nations - UN/EDIFACT (Electronic Data Interchange for Administration, Commerce and Transport) [1]. Although this may be somewhat unexpected at the time of XML services, Internet \& WWW, EDI is still the most widely used format in electronic commerce transactions in the world.

\section{Current Situation, Problems, Issues}

In Kosovo, currently one of the main objectives of information society development is that it need to be in full compliance with the criteria and standards applied in EU. For this reason, the Agency for Information Society (hereinafter referred to as AIS) was established as a central agency for the institutions of the Republic of Kosovo (hereinafter referred to as IRK) of Information Technology and Communication (hereinafter ICT). This process was followed by some documents describing goals and tasks in the area of E-Government: Strategy 2009-2015, Action Plan 2014-2016, Interoperability Framework [2]. AIS plays an important role in implementing the tasks deriving from these documents in practice [3], [4]. Various state institutions in the Republic of Kosovo have developed their own IT systems. At this point it is necessary to analyze the current situation and the existing main systems and the data exchange capabilities between them. This is especially the Ministry of Finance, Tax Administration, Customs Administration, Ministry of Trade and Industry, Ministry of Agriculture, Ministry of Economic Development, Cadastral offices, Food and Veterinary Agency. The goal is to make the systems that related to trade and the development of the economy are able to communicate properly among themselves.

The research team made up of authors of this paper, based on known information and interviews, has identified that AIS currently provides other institutions with 11 e-services. It has also found that currently offer exchange of data from central and local institutions through 27 interconnections. Usually these connections are Web services.

The information provided showed that data structures, in existing interconnections, contained mostly only the names of the data elements as well as the type of data and their maximum size. During the research, there were difficulties in obtaining complete data structures of selected systems for analysis by the research team, therefore it was not possible to conduct a thorough analysis of existing data structures.

Findings in the existing electronic registry that were the object of study:

The Civil Registry - knowing that the system itself is classified as confidentiality, according to the description of the connection - a Web service that is provided to central and local institutions. The information provided to the registry contained only names of the data elements for the physical person.

The Cadastral Registry - contains the basic addresses, and its data are related to other registers and information systems of central and local institutions.

The Tax Registry - the constituent parts of the tables are the names of the particular elements of the data, the type of data and the maximum size of the data field.

The Enterprise and Investment Support Register - contained the names of data elements for legal entities and data elements for physical persons.

The Customs Registry - from an example is identified the description of metadata with its interconnections.

Continuing the study

The research team has prepared a list of data elements and based on data element semantics has created a set of compatible and incompatible data elements. 
After comparing and evaluating the compatible set of components, the recommendation is harmonizing and creating data dictionaries.

\section{Result of the study}

Based on the provided information finding was not possible to determine the dependencies between the individual elements of the data. For this, it is necessary to have data models of information systems available.

\section{Compatible Data Element Groups}

From semantic perspective, a set of data elements is repeatedly repeated in the databases, as in the following fields:

- data describing the physical person;

- data describing the legal entity;

- data describing address book entries.

As a basis harmonizing records describing the physical person, we recommend using the data structure from the civil register. First, the civil register uses its databases with standardized data elements and secondly, this web service is used by a large number of information systems from central and local institutions.

As a basis for harmonizing data describing the legal entity, we recommend using a data structure used by the business register.

For the harmonization of address data, we recommend the use of default data from the Kosovo Cadaster Information System. First of all it is preferable to compare this set of notes with ISO standards.

\section{Incompatible Data Elements Groups}

Since the team only received surface notes that were completely missing data codes and data, it was not possible to identify the incompatible data group for further splitting.

\section{Proposals of solution for interoperability of Information Systems}

A summary of the analysis shows that public institutions are already fully available infrastructure of information systems, National Data Center. At the same time it is in preparation for the development of new information systems. Based on this situation the team proposes the solution of interaction through the integration of data. This method does not require large investments in infrastructure such as hardware or software, because it is largely based on organizational and methodological tools, standardization and harmonization of data structures, information systems central and local level. There is an advantage because they depend directly on the development teams of their information systems or their advancements. The above method is implemented within the framework of E-Government continuously throughout the life cycle of information systems. But the difficulties remain in the organization of individual activities.

In the case of the full implementation of the ISO/IEC 11179 recommendations in the framework of E-Government, 3 tier level is applied in the national, departments and information systems. Knowing the current situation, it is recommended to apply the standard with modifications. This means using only 2 levels tier of national and information system level and limiting the number of roles in the data management system. 
The research team recommends the creation of work center at the central state level Central Management Data and Codes that would provide support and services to individual development teams and information management teams.

The data integration database, in addition to the process of harmonizing data elements and their codes, is data management. This should be gradually introduced into the various information systems and fully supported by the central data and code manager, also with the creation and management of the data element and code catalog.

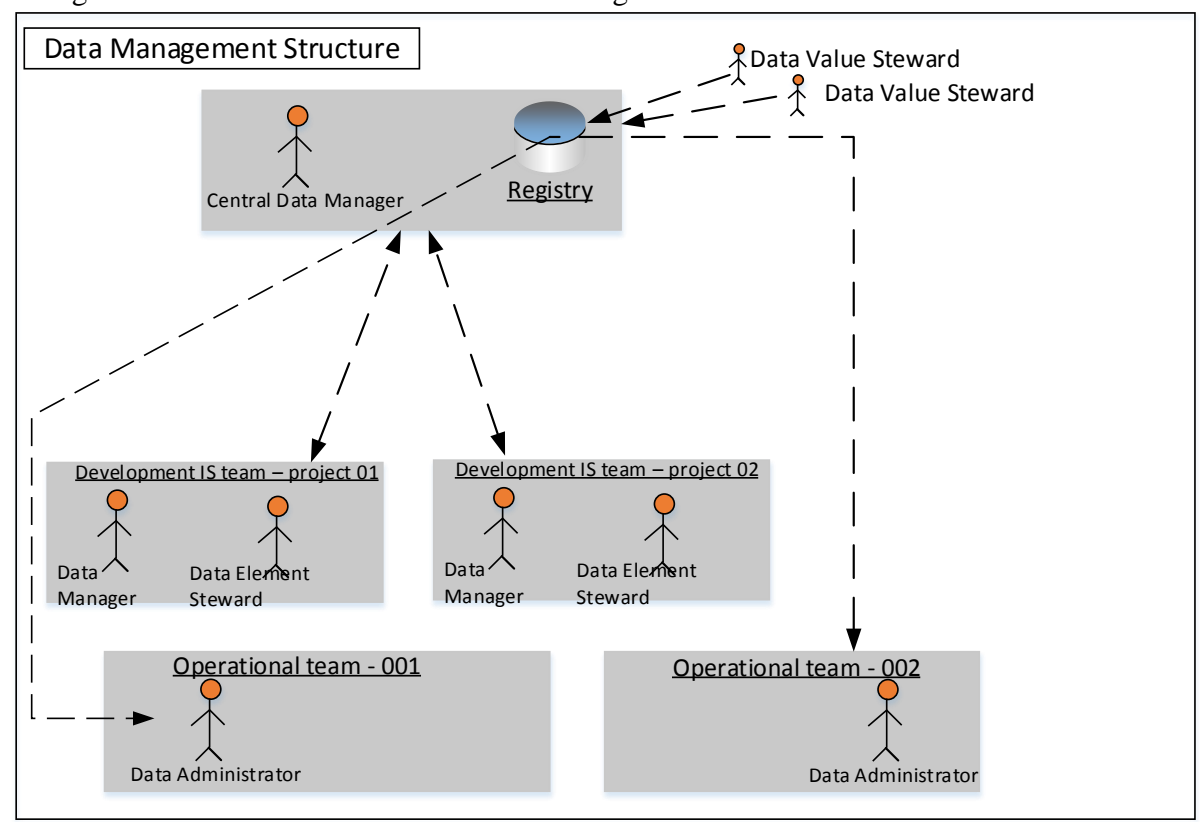

Figure 4 Data Management Structure

The central work center called the Central Management of Data and Codes consist of: Data Manager, Data Element Stewards, VD Stewards, and Data Administrator.

\section{Economical benefits}

A condition for the effective management of support for state management agendas, is the quality of information provided to users of information systems. Maximum attention is paid to the methods of data creation and management. The quality of these processes creates conditions for the following areas, which creates conditions for improving IT quality support various government processes and to achieve direct and indirect economic benefits. It's about:

- With the unification and harmonization of data elements, will increase their quality and presentation capability.

- With the applied technology of standardization for their transfer to interactive information systems comes the reduction of errors and the creation of conditions for their further use.

This makes it easier and economically cheaper, for example in Tax and Customs administration, where tax evasion and customs fraud can be successfully detected. The analysis of available data structures may reveal shortcomings in building information systems, such as 
the effectiveness of subsidies. A series of economic analyzes of selected indicators can be made for example the costs of selecting specific types of taxes and a range of other activities such as investment efficiency etc.

According to the recommendations of this research, other benefits may be cost reduction for the modification and creation of information systems, where through good management of electronic registry and communication standards, development costs will be reduced.

An important economic benefit, we see increased quality of processes in the development of tender documentation of new information systems.

\section{Conclusion}

In researching this scientific paper, long experience in public administration, exchange of experiences and experiences in different EU countries, Asia and the USA has been used.

In researching and conducting various analyzes the research team has come to a conclusion identifying the main obstacle to effective communication between public institutions in Kosovo, which is the incompatibility of the data structure.

The way and solution for eliminating incompatibility of data is to create a catalog of harmonized data elements, namely the metadata register.

\section{References}

1. ISO 9735-1:2002 Electronic data interchange for administration, commerce and transport (EDIFACT) - Application level syntax rules (Syntax version number: 4, Syntax release number:1) - Part 1: Syntax rules common to all parts

2. Interoperability Framework of the Republic of Kosovo, Ministry of Public Administration, Pristina

3. Law No. 04/L-145 no Information Society Government Bodies, Pristina, 2013

4. Regulation (GRK) No. 02/2016 For coordination between the Agency for Information Society and organizational structures/Information and communication technology officials in institutions of Republic of Kosovo, Pristina, 2016 